\title{
The bitter news about sweet solutions for the post neonatal age
}

\author{
Ran D. Goldman ${ }^{1}$
}

Received: 3 August 2021 / Accepted: 6 August 2021

(C) The Author(s), under exclusive licence to Canadian Association of Emergency Physicians (CAEP)/ Association Canadienne de Médecine d'Urgence (ACMU) 2021

Over the last several decades, providers, parents, and the scientific community realized the importance of managing pain in children, to reduce anxiety, distress, and fear associated with procedures. These are all shown to result in long-term fears of needles, and avoidance of medical care [1].

Common procedures in a hospital and clinic settings include the "heel prick" for blood draw in neonates, immunization throughout childhood, and intravenous blood testing. Emergency medicine providers are responsible for a myriad of other painful procedures taking place daily in the emergency department (ED), such as bladder catheterization, lumbar puncture, and nasopharyngeal aspiration.

Canadian investigators are a powerhouse in the study of pain and have been leading the effort to uncover the value of non-pharmacological analgesia. High-quality synthesized evidence demonstrates analgesic effects of breastfeeding, skin-to-skin contact (kangaroo care), and sweet-tasting solutions [2].

The exact mechanism of action of oral sweet solutions in infants is not clear, and thought to include an orally mediated release of endogenous opioids. Yet, sucrose was found in a number of systematic reviews written by Canadians to be effective in reduction of procedural pain in preterm and term infants, with a very favourable safety profile [3].

However, the 'jury is still out' on whether sweet solutions have an analgesic effect for those over one month of age. For children 1-3 months old, oral sucrose was not better than placebo for pain during venipuncture [4] or IV cannulation in the ED [5]. A Cochrane review found insufficient evidence that sweet tasting solutions work for children

Ran D. Goldman

rgoldman@cw.bc.ca

1 The Innovative Pain Lab, Pediatric Research in Emergency Therapeutics (PRETx) Program, Division of Emergency Medicine, Department of Pediatrics, University of British Columbia, and the BC Children's Hospital, 4480 Oak St, Vancouver, BC, Canada
1-4 years of age during painful procedures, and reported no evidence for analgesic effect in school aged children [6].

In this issue of CJEM, Desjardins et al. from Centre Hospitalier Universitaire Sainte-Justine, Université de Montréal, found that in infants 1-3 months of age oral sweet solution did not provide an analgesic effect when undergoing bladder catheterization in the ED [7]. The validated Face, Legs, Activity, Cry and Consolability (FLACC) Pain Scale, the Neonatal Infant Pain Scale (NIPS), crying time, variations in heart rate and adverse events were similar for children receiving sweet solution or placebo.

These findings demonstrate, in conjunction with prior reports about oral sweet solutions in this age group, that what works for neonates (up to 28 days of life) may not work for older infants (one month of age and older). Similar to the erroneous assumption that children are 'just small adults', drugs can not be used for the same indications among children and adults, and dosages can not be derived or estimated for children based on findings in adults. Prescribers should not assume that what has been proven to benefit neonates can be used in older children without rigorous clinical trials. School-aged children and adolescents may be even further afield, in terms of response to those measures. Before implementing analgesia protocols in the ED, sufficient high-quality research should uncover the efficacy and adverse effects of any potential remedy_pharmacological or non-pharmacological.

Nowadays, the same concept is implemented in the testing of a vaccine against COVID-19. New adverse events, including pericarditis and myocarditis, have been reported in the groups of adolescents receiving an mRNA vaccine, prompting safety concerns that were not reported at the same rate in older adults [8]. Similarly, approval of vaccines for children as young as 6 months of age will wait until enough data are collected to demonstrate effectiveness and safety in the younger age groups, despite parents' pressure to accept expedited vaccine research and forego safety-related regulation [9]. 
This age-differentiation promise also means that scales used to assess pain in children should first be developed and prospectively validated for separate age groups, before we use them for older or younger children. ED providers must remember that procedures may pose diverse levels of pain, and even different vaccines and the order they are given may be experienced differently among children [10].

While sweet oral solutions are by far better than the promoted over-the-counter combination of sugar, alcohol, and opium, distributed in the 1800's to treat pain and to calm young infants (Perry Davis Vegetable Pain Killer), we are still searching for better pain-management strategies in the ED for infants in the post neonatal age.

\section{Declarations}

Conflict of interest The author declare that they have no conflict of interest.

\section{References}

1. Diekema DS. Improving childhood vaccination rates. N Engl J Med. 2012;366(5):391-3. https://doi.org/10.1056/NEJMp11130 08 (PMID: 22296072).

2. Harrison D, Larocque C, Bueno M, et al. Sweet solutions to reduce procedural pain in neonates: a meta-analysis. Pediatrics. 2017;139(1):e20160955.

3. Stevens B, Yamada J, Ohlsson A, Haliburton S, Shorkey A. Sucrose for analgesia in newborn infants undergoing painful procedures. Cochrane Database Syst Rev. 2016;7(7):CD001069. https://doi.org/10.1002/14651858.CD001069 (PMID: 27420164; PMCID: PMC6457867).
4. Gouin S, Gaucher N, Lebel D, Desjardins MP. A randomized double-blind trial comparing the effect on pain of an oral sucrose solution vs. placebo in children 1 to 3 months old undergoing simple venipuncture. J Emerg Med. 2018;54(1):33-9. https://doi. org/10.1016/j.jemermed.2017.08.015 (Epub 2017 Nov 3. PMID: 29108736).

5. Desjardins MP, Gaucher N, Curtis S, LeMay S, Lebel D, Gouin S. A randomized controlled trial evaluating the efficacy of oral sucrose in infants 1 to 3 months old needing intravenous cannulation. Acad Emerg Med. 2016;23(9):1048-53. https://doi.org/10. 1111/acem.12991 (Epub 2016 Sep 7 PMID: 27098499).

6. Harrison D, Yamada J, Adams-Webber T, Ohlsson A, Beyene J, Stevens B. Sweet tasting solutions for reduction of needlerelated procedural pain in children aged one to 16 years. Cochrane Database Syst Rev. 2015;2015(5):CD008408. https://doi.org/10. 1002/14651858.CD008408.pub3 (PMID: 25942496; PMCID: PMC6779143)

7. Desjardins MP, Gaucher N, Gravel J, Lebel D, Gouin S. A randomized double-blind trial comparing the effect on pain of an oral sucrose solution versus placebo in children 1-3 months old needing bladder catheterization. CJEM. 2021. https://doi.org/10.1007/ s43678-021-00130-x (Epub ahead of print. PMID: 34037975).

8. Bozkurt B, Kamat I, Hotez PJ. Myocarditis with COVID-19 mRNA vaccines. Circulation. 2021. https://doi.org/10.1161/ CIRCULATIONAHA.121.056135 (Epub ahead of print. PMID: 34281357).

9. Goldman RD, Marneni SR, Seiler M, Brown JC, Klein EJ, Cotanda CP, Gelernter R, Yan TD, Hoeffe J, Davis AL, Griffiths MA, Hall JE, Gualco G, Mater A, Manzano S, Thompson GC, Ahmed S, Ali S, Shimizu N; International COVID-19 Parental Attitude Study (COVIPAS) Group. Caregivers' willingness to accept expedited vaccine research during the covid-19 pandemic: a cross-sectional survey. Clin Ther. 2020;42(11):2124-33. https://doi.org/10.1016/j.clinthera.2020.09.012 (Epub 2020 Oct 3. PMID: 33067013; PMCID: PMC7532744).

10. Ipp M, Parkin PC, Lear N, Goldbach M, Taddio A. Order of vaccine injection and infant pain response. Arch Pediatr Adolesc Med. 2009;163(5):469-72. https://doi.org/10.1001/archpediat rics.2009.35 (PMID: 19414694). 